\title{
O COMENTÁRIO METADISCURSIVO COMO ESTRATÉGIA ARGUMENTATIVA EM DEBATES ELEITORAIS ${ }^{i}$
}

\author{
Gustavo Ximenes Cunhaii \\ Paloma Bernardino Bragaii
}

Resumo: Neste trabalho, investigamos o papel do comentário metadiscursivo (CM) como uma estratégia argumentativa relevante, utilizada pelos adversários políticos no debate eleitoral. Com base na análise de dois debates, verificamos que, do ponto de vista da função que exercem, todos os $C M$ atuam no processo de negociação de faces (ou trabalho de face). A partir dessa função geral, identificamos três subtipos de $\mathrm{CM}$, que são aqueles com que os adversários (i) avaliam negativa ou positivamente a maneira como o interlocutor (adversário ou integrante da plateia) construiu sua intervenção, (ii) avaliam o comportamento dos candidatos ao longo do debate ou mesmo ao longo da campanha eleitoral, (iii) evidenciam ter consciência de propriedades típicas (regularidades genéricas) da interação de que participam.

Palavras-chave: Comentário metadiscursivo. Debate eleitoral. Estratégia argumentativa. Trabalho de face.

Abstract: In this paper, we investigate the role of metadiscursive comments (MC) as a relevant argumentative strategy, used by political opponents of electoral debates. Based on the analysis of two debates, we note that, from the point of view of function, all MC act in the process of face work. From this general function, we have identified three subtypes of $M C$, which are those that (i) evaluate negatively or positively the way the interlocutor (opponent or member of the audience) builds its intervention, (ii) evaluate the behavior of the candidates in the debate or even along the electoral campaign, (iii) evidence that the interlocutors are aware of the typical properties (generic regularities) of the interaction.

Keywords: Metadiscursive comment. Electoral debate. Argumentative strategy. Face work.

\footnotetext{
'Este trabalho, que desenvolve uma versão preliminar apresentada em Cunha (2016), expõe os resultados iniciais do projeto de pesquisa intitulado "O papel do comentário metadiscursivo na construção de debates eleitorais", que conta com o apoio do CNPq.

ii Doutor em Linguística pela Universidade Federal de Minas Gerais (UFMG) e Professor Adjunto da Faculdade Letras da UFMG. E-mail: ximenescunha@yahoo.com.br.

iii Graduanda em Letras pela Faculdade de Letras da Universidade Federal de Minas Gerais (UFMG) e bolsista de Iniciação Científica (PIBIC/CNPq). E-mail: palomabbraga@gmail.com.
} 
EID\&A - Revista Eletrônica de Estudos Integrados em Discurso e Argumentação, Ilhéus, n. 12, jul/dez.2016.

\section{Considerações iniciais}

Enquanto estabilização sócio-histórica de um saber-fazer, uma prática social se constitui de um conjunto de expectativas sobre como agir nessa prática, as quais são compartilhadas pelos integrantes de um dado grupo social (FILLIETTAZ, 2000). Isso significa que, dependendo do processo de socialização por que tenha passado, cada agente é dotado de expectativas relativas a como ele e os outros devem agir verbalmente ou não em cada prática social a que tenha sido repetidamente exposto. Em qualquer grupo, essas expectativas são recursos poderosos com os quais cada agente pode avaliar sua conduta, bem como a conduta dos co-agentes ao longo de uma atividade social particular. Afinal, embora remodeláveis, essas expectativas possuem um caráter normalizador ou padronizador das atividades sociais particulares, sendo alvo de sanções sociais de vários tipos aquele que deliberadamente ou não as transgride.

Nessa perspectiva, a linguagem verbal ganha extrema relevância, na medida em que, por meio dela, os agentes evidenciam suas expectativas acerca da prática social a que pertence a atividade que desenvolvem conjuntamente. Em outros termos, todas as ações linguageiras que os agentes realizam ao longo de uma interação evidenciam quais são, para eles, as linhas de conduta esperadas para aquele encontro ou para aquele tipo de prática social (GOFFMAN, 2011).

Neste trabalho, buscamos compreender o papel que o comentário metadiscursivo (doravante $\mathrm{CM}$ ) desempenha em uma prática social definida, $\mathrm{o}$ debate eleitoral. Partimos da hipótese de que esse tipo de comentário revela as expectativas dos adversários políticos acerca da prática de que participam, já que esses comentários tematizam exatamente as linhas de conduta por eles assumidas no decorrer do debate. Partindo dessa hipótese, o objetivo deste trabalho é evidenciar que o CM constitui uma estratégia argumentativa com a qual cada adversário busca, ao mesmo tempo, convencer o espectador/eleitor de que ele, tendo em vista a linha de conduta que segue durante o debate, é a melhor alternativa para o cargo em disputa e de que o oponente, também em virtude da linha que escolhe seguir, demonstra despreparo para o cargo.

Neste artigo, definiremos, inicialmente, as noções de debate eleitoral e de comentário metadiscursivo. Em seguida, com base em dois debates - um ocorrido durante a campanha pela prefeitura de São Paulo em 2012 (Fernando Haddad (PT) e José Serra (PSDB)) e um ocorrido durante a campanha 
EID\&A - Revista Eletrônica de Estudos Integrados em Discurso e Argumentação, Ilhéus, n. 12, jul/dez.2016.

presidencial de 2014 (Dilma Rousseff (PT) e Aécio Neves (PSDB)), promovidos pelo mesmo veículo de comunicação, a Rede Globo -, explicitaremos em que medida o CM, porque revela as expectativas dos adversários políticos acerca do debate, constituem um recurso importante com que cada um avalia sua conduta e a do oponente, na tentativa de influenciar o espectador.

\section{1. $O$ debate eleitoral}

O debate constitui uma prática social que possui um grau elevado de complexidade devido ao fato de se caracterizar pela articulação dos domínios jornalístico e político (CHARAUDEAU, 2013; CUNHA, 2015). Por ser um produto de uma emissora de televisão e, por isso mesmo, precisar ser o mais atrativo possível para o maior número de espectadores e de anunciantes, o debate eleitoral possui um caráter de entretenimento. Assim, o debate eleitoral pode ser entendido como um "espetáculo da democracia", já que é uma forma de entretenimento que coloca o cidadão como instância poderosa (CUNHA, 2016).

O que torna o debate um produto midiático atrativo é o fato de que nele há um traço característico de construção polêmica. Cada debatedor tenta desestabilizar o oponente, por meio de acusações, negações e até mesmo ofensas, fazendo o telespectador/eleitor crer que este não seria a melhor escolha para seu voto. Além disso, os candidatos, durante o debate, negociam suas imagens identitárias', tentando reivindicar valores sociais positivos para si (preservação da própria face) e atribuir valores sociais negativos ao adversário (ataque à face alheia), valendo-se de recursos retóricos, linguísticos, textuais e discursivos, tornando o debate polêmico e, por consequência, atrativo (AQUINO, 2008, SILVA, 2013).

No que se refere à sua estrutura, o modo como o espaço do debate é estruturado pode aumentar ou diminuir o nível de agressividade entre os adversários (SOARES; GOMES, 2008), o que indica que o cenário onde o debate se desenvolve não é um espaço apenas físico, mas também simbólico, por ser repleto de significações. O cenário do debate pode ter diversos formatos, como o pictórico, o oval e o octagonal (remetendo ao ringue de

\footnotetext{
${ }^{1}$ Neste trabalho, a noção de imagem identitária corresponde à de face, tal como proposta por Goffman (2011, p. 13-14): "valor social positivo que uma pessoa efetivamente reivindica para si mesma através da linha [de conduta] que os outros pressupõem que ela assumiu durante um contato particular"; "é a imagem do eu delineada em termos de atributos sociais aprovados".
} 
luta), cada formato possibilitando maior ou menor liberdade de movimento aos participantes. Se no debate os candidatos devem se posicionar, ao longo de toda a interação, em um púlpito, sua liberdade de movimento fica limitada, favorecendo, assim, a constante troca de olhares e o confronto face a face direto. Esse formato propicia um aumento da agressividade. Esse é o formato que caracterizou um dos debates que compõem nosso corpus e que foi protagonizado por Fernando Haddad e José Serra, como mostrado na Figura 1:

Figura 1: Debate Fernando Haddad e José Serra.

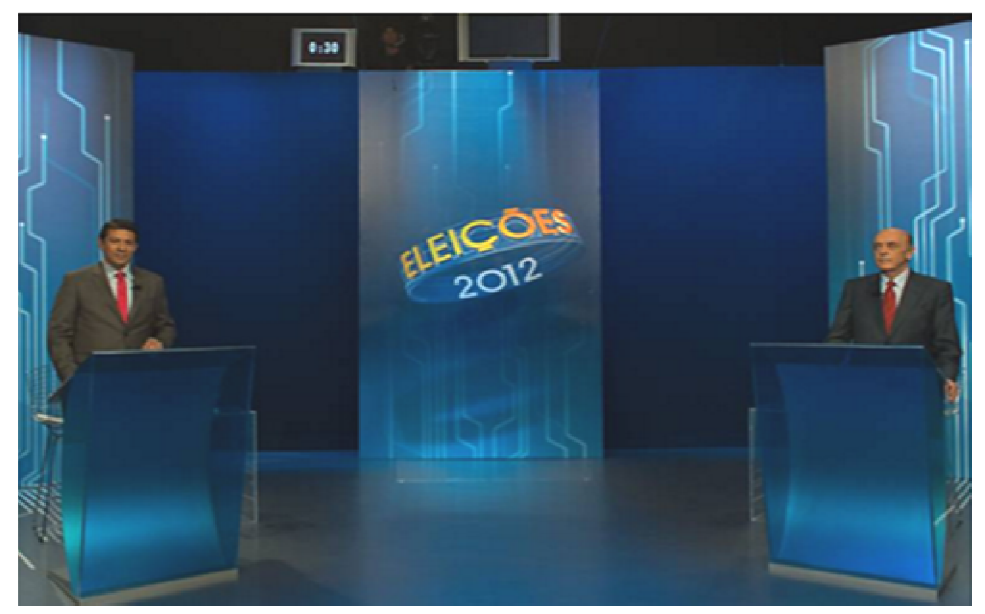

Fonte: Jornal Folha de S. Paulo.

Mas, se no debate não há presença de um púlpito, os debatedores têm relativa liberdade para circular pelo cenário. Nesse formato, é comum haver a presença de uma plateia no estúdio de televisão onde ocorre o debate. Se, por um lado, a ausência de um confronto face a face constante pode diminuir a agressividade, a presença da plateia com suas reações (aplausos, vais, risos etc), por outro, pode tornar o ambiente mais tenso e, consequentemente, aumentar a agressividade dos candidatos. Esse é o formato que caracterizou o outro debate que compõe nosso corpus e que foi protagonizado por Dilma Rousseff e Aécio Neves, como evidencia a Figura 2: 
Figura 2: Debate Dilma Rousseff e Aécio Neves

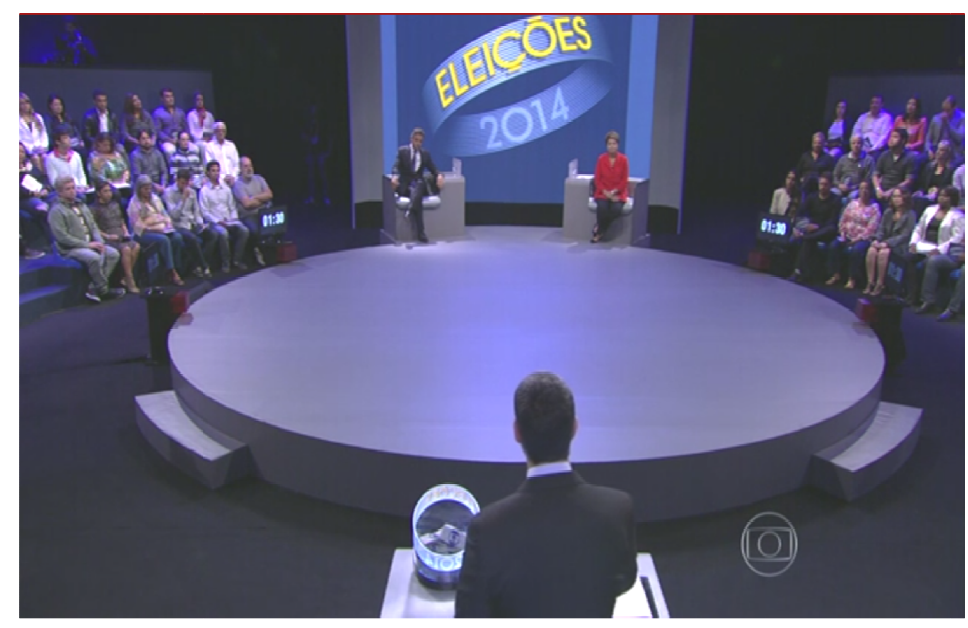

Fonte: Portal G1.

Como se pode notar, o debate é uma prática social complexa e elaborada para ser polêmica e atrativa, o que implica que os personagens centrais dessa prática (os adversários políticos) saibam usar a linguagem para desestabilizar a imagem do(s) oponente(s) e afirmar ou reafirmar a sua. Como parte das estratégias argumentativas de que os candidatos se valem, o CM, como veremos nos próximos itens, constitui recurso importante com que os candidatos realizam essa negociação de imagens identitárias.

\section{O comentário metadiscursivo}

O CM pode ser definido como uma operação metadiscursiva (RISSO; JUBRAN, 1998) por meio da qual o produtor do discurso (oral ou escrito) avalia seu próprio discurso ou o discurso de outra instância enunciativa (o interlocutor ou um terceiro). Como salienta Jubran (2005, p. 220), "no metadiscurso, as palavras são usadas para referirem-se à própria atividade discursiva, indicando a introjeção da instância da enunciação na materialidade textual". Assim, diferentemente do comentário que toma como objeto de discurso as proposições expressas pelas instâncias enunciativas, o metadiscursivo toma como objeto de discurso a própria enunciação. A título de ilustração, vejamos estes dois segmentos, ambos retirados da fala de Haddad no debate travado com Serra e integrante do corpus desta pesquisa: 
EID\&A - Revista Eletrônica de Estudos Integrados em Discurso e Argumentação, Ilhéus, n. 12, jul/dez.2016.

(01) Fernando Haddad: É obrigação do prefeito buscar recursos federais, inclusive na área social, para o transporte que vai mal, para a saúde que vai mal, para a educação de São Paulo.

(02) Fernando Haddad: Serra, eu queria voltar à questão dos corredores. Você procura tangenciar essa questão, afinal de contas você é a favor ou contra?

Em (01), por meio dos comentários sublinhados, Haddad avalia a qualidade do transporte e da saúde na cidade de São Paulo. Já em (02), o candidato faz uma avaliação acerca da atitude do adversário, que estaria, segundo Haddad, evitando dar uma resposta direta para a questão dos corredores de ônibus. Porque o comentário em (02) recai sobre um aspecto relativo ao contexto discursivo, que é o comportamento linguageiro de um dos interlocutores, esse seria uma ocorrência de comentário metadiscursivo. Dessa forma, o CM recai sobre o dizer (ou sobre a própria enunciação) e não sobre o dito (DUCROT, 1987).

Em perspectiva teórica semelhante, Kotschi (1986) considera o CM como um ato de composição textual, ao lado de atos como reformular, justificar, resumir, parafrasear. Nesse sentido, o CM seria uma categoria de relação de discurso por meio da qual o locutor, articulando um enunciado-origem e um enunciado-comentativo, utilizaria o segundo enunciado para comentar o primeiro. Entretanto, vale ressaltar que, ao contrário da caracterização proposta por Kotschi, nem sempre a avaliação feita no CM recai sobre o enunciado imediatamente anterior ao comentário. É o que evidencia o exemplo (03), que constitui a parte inicial de uma intervenção produzida por Serra no mesmo debate mencionado anteriormente:

(03) José Serra: Fernando, preliminarmente eu permito dizer que você está muito nervoso, muito agressivo, eu acho que isso não ajuda a qualidade do nosso debate, com toda a franqueza.

Nesse exemplo, a fala de Serra constitui um CM que não se liga a nenhum enunciado-origem, já que não recai sobre um enunciado produzido pelo candidato ou por seu adversário, mas sim sobre a própria linha de conduta ou o comportamento assumido por este. Por isso, com base em Roulet (2003, 2006), propomos caracterizar o CM como um tipo de relação de discurso em que um CM se articula a uma informação previamente estocada na memória discursiva dos interlocutores ${ }^{2}$. Com essa especificação, buscamos

\footnotetext{
${ }^{2}$ A memória discursiva corresponde ao "conjunto de saberes conscientemente partilhados pelos interlocutores" (BERRENDONNER, 1983, p. 230). Ela abarca "os diversos pré-requisitos culturais
} 
EID\&A - Revista Eletrônica de Estudos Integrados em Discurso e Argumentação, Ilhéus, n. 12, jul/dez.2016.

dar conta do fato de que um CM pode se articular a informações com origem tanto em enunciados particulares (ou, mais precisamente, no modo como foram enunciados), quanto em aspectos não verbalizados na interação.

Do ponto de vista da função que os CM podem exercer no discurso, observa Kotschi (1986, p. 221): "Cada um desses enunciados permitiria, portanto, ao locutor sinalizar o questionamento de uma norma dada (e geralmente um afastamento - mesmo mínimo - dela) e, ao mesmo tempo, evocar uma formulação [...] que corresponderia (melhor) a essa norma" Ao apontar que os CM têm o papel de permitir ao locutor questionar uma dada norma, Kotschi reforça que, por meio desse tipo de comentário, os interlocutores podem fazer avaliações acerca de normas sociais que subjazem à interação e ao uso da linguagem nessa interação. E, ao fazerem avaliações por meio de $C M$, os interlocutores expressam uma tomada de posição, revelando graus variados de aceitação ou rejeição quanto ao objeto avaliado (as atitudes tomadas pelos interlocutores, o desvio de alguma norma de condução da interação, a pertinência ou não das palavras utilizadas etc) (BONU, 2001).

O exemplo (03) nos permite evidenciar o funcionamento de um $\mathrm{CM}$. Nesse exemplo, ao comentar o comportamento de Haddad, Serra tenta revelar (para o espectador) que o adversário estaria infringindo expectativas de ordem social acerca de como candidatos a um cargo público devem se comportar num debate. Segundo Serra, um debate de "qualidade" pressupõe o embate de ideias e não a agressão ou o nervosismo. Com esse comentário, o candidato parece querer mostrar ao eleitor que o adversário não sabe participar de um diálogo democrático. Em última instância, o adversário não estaria apto a assumir o cargo político que reivindica. Em resposta ao $\mathrm{CM}$ de Serra, Haddad rebate com outro $\mathrm{CM}$ em que também tematiza seu próprio comportamento (trecho sublinhado):

(04) Fernando Haddad: Serra, na verdade o que você nota de nervosismo é indignação, eu corri essa cidade inteira e eu passei pelos bairros mais pobres dessa cidade, não sei se você foi ao jardim Peri, eu não sei se você foi a Vila Bela, eu não sei se você está acompanhando o que está acontecendo na Cidade de São Paulo. [...]

(normas comunicativas, lugares argumentativos, saberes enciclopédicos comuns etc) que servem de axiomas aos interlocutores para conduzir uma atividade dedutiva" (BERRENDONER, 1983, p. 230-231) e é alimentada tanto pelos acontecimentos extralinguísticos como pelos enunciados sucessivos do discurso. 
Refutando a alegação do adversário de que estaria adotando um comportamento inadequado para um debate e, portanto, infringindo uma norma social, Haddad comenta seu comportamento, revelando (ao eleitor) que seu suposto nervosismo é, na verdade, indignação pelas condições de vida da população. Assim, por meio da troca de CM sobre o comportamento de Haddad, os candidatos expressam sua tomada de posição sobre um elemento da situação comunicativa. Tendo sempre o espectador como alvo, Serra quer convencê-lo de que a linha de conduta seguida pelo adversário no debate é uma evidência de sua incapacidade, enquanto Haddad quer convencer o mesmo espectador de que sua linha de conduta é, ao contrário, uma qualidade necessária a um político.

Como se pode constatar, o CM é um fenômeno discursivo complexo, na medida em que articula informações de diferentes planos da organização do discurso, tais como a construção da cadeia referencial (ativação e reativação de objetos de discurso), as relações de discurso (ligação de constituintes do texto e informações da memória discursiva), a polifonia (retomada, aceitação e rejeição de discursos sustentados pelo próprio locutor e por outros), bem como informações de natureza lexical, sintática e prosódica (ROULET, FILLIETTAZ \& GROBET, 2001). Ainda que neste trabalho não possamos proceder a uma descrição pormenorizada de cada um desses aspectos envolvidos no estudo do $\mathrm{CM}$, no próximo item analisaremos o papel do $\mathrm{CM}$ em dois debates eleitorais, lançando mão, ainda que de maneira assistemática, desses diferentes planos da organização do discurso.

\section{O comentário metadiscursivo em debates eleitorais}

Como informado na introdução, o corpus desta pesquisa é formado por dois debates eleitorais. $O$ debate entre Fernando Haddad (PT) e José Serra (PSDB) aconteceu em 26/10/2012, no segundo turno da campanha eleitoral pela prefeitura de São Paulo, e foi transcrito e publicado pelo jornal Folha de S. Paulo, no dia posterior ao do debate 3 . Já o debate entre Dilma Rousseff (PT) e Aécio Neves (PSDB) ocorreu em 24/10/2014, no segundo turno da campanha

\footnotetext{
${ }^{3}$ O debate completo pode ser acessado em: <http://www1.folha.uol.com.br/poder/1176189-leia-atranscricao-do-debate-da-tv-globo-entre-candidatos-a-prefeito-de-sp.shtml>.
} 
EID\&A - Revista Eletrônica de Estudos Integrados em Discurso e Argumentação, Ilhéus, n. 12, jul/dez.2016.

pela Presidência da República, tendo sido transcrito e publicado no portal $\mathrm{G} 1^{4}$. Os dois debates foram promovidos pela Rede Globo.

Ao longo dos debates, mas predominantemente na abertura e no fechamento dos blocos, os jornalistas-moderadores fazem intervenções, em que explicam ou relembram a dinâmica do debate. Essas intervenções são metadiscursivas, já que sempre recaem essencialmente sobre os comportamentos linguageiros que os candidatos devem assumir ao longo da interação. Porém, como a "razão de ser" do debate são as intervenções dos candidatos, nossa pesquisa se ocupa apenas dos CM que ocorrem em suas falas.

Tratando especificamente dos $\mathrm{CM}$ produzidos pelos adversários políticos, a análise dos debates desenvolvida até o atual momento da pesquisa permitiu constatar a existência de uma série de regularidades na forma como os candidatos empregam esses comentários, bem como nas funções que eles exercem.

Do ponto de vista da forma, a maior parte dos CM identificados até o momento ocorre no início das intervenções dos candidatos. De modo geral, são comentários curtos, que fazem a "ligação" entre a intervenção anterior e a parte central da intervenção encabeçada pelo $\mathrm{CM}$, como evidencia este exemplo:

(05) Dilma Rousseff: Candidato, eu sempre gosto de perguntar a respeito do Pronatec. [...] Vocês fizeram uma lei proibindo que o governo federal fizesse e mantivesse escolas técnicas. Por isso fizeram, ao longo de oito anos, só 11 escolas técnicas. O senhor era líder do governo FHC. O senhor vai continuar com essa política?

Aécio Neves: Eu não devia lhe corrigir em público, mas eu era líder do PSDB, mas vamos passar isso, deixar isso um pouco mais barato. É, mais ou menos candidata. Para quem não conhece o Congresso Nacional, talvez sim, mas é muito diferente, é muito diferente.

William Bonner: Por favor. Vou pedir silêncio [da plateia] mais uma vez.

Aécio Neves: Candidata, o Pronatec é uma inspiração e é bom reconhecer isso.

Nesse trecho do debate entre Dilma Rousseff e Aécio Neves, a parte sublinhada na fala do então candidato corresponde a um CM que articula a pergunta feita pela adversária à resposta que se inicia após a intervenção do jornalista-moderador. A parte sublinhada é um CM, não só porque promove uma correção da fala da adversária e, portanto, da linha de conduta assumida por ela, mas também porque revela o conhecimento do candidato de normas sociais que seriam adequadas ou inadequadas em um debate ou das regras

4 O debate completo pode ser acessado em: <http://g1.globo.com/politica/eleicoes/2014/transcricao-debate-presidencial-2-turno.html>. 
EID\&A - Revista Eletrônica de Estudos Integrados em Discurso e Argumentação, Ilhéus, n. 12, jul/dez.2016.

que subjazem ao debate. Assim, a primeira sentença (Eu não devia lhe corrigir em público) constitui um ato desarmador (KERBRAT-ORECCHIONI, 2006) por meio do qual o candidato, simulando polidez, prepara a adversária para o ataque que fará à sua face no restante do $\mathrm{CM}$, principalmente no segmento Para quem não conhece o Congresso Nacional, em que acusa indiretamente a então Presidenta da República de não conhecer o Congresso Nacional. Com o ato desarmador, o candidato demonstra saber não ser "de bom tom" corrigir alguém em público, mesmo que esse alguém seja um adversário político, e, por isso, revela a força ilocucionária (correção) de toda a intervenção que produz.

Como aponta esse exemplo, é comum, nos CM, o candidato revelar qual é, para ele, a força ilocucionária ou o efeito perlocucionário da intervenção que ele mesmo produz, da intervenção previamente produzida pelo adversário ou de intervenção produzida por terceiros, em momento anterior ao debate. Assim, nos dois debates que compõem nosso corpus, há ocorrências de $\mathrm{CM}$ em que a intervenção previamente produzida pelo adversário ou por terceiros é interpretada como acusação, correção, ofensa, pergunta, resposta, crítica, calúnia, difamação etc, como mostram estes exemplos.

(o6) Fernando Haddad: Minha dificuldade em compreender a resposta é o fato de que boa parte da administração Kassab tem os secretários indicados pelo Serra. [...]

(07) José Serra: Olha, nessa questão do metrô, também fala-se muito quando se critica, mas propõe-se pouco. [...]

(08) Dilma Rousseff: [...] Agora essa revista [Veja] que fez e que faz sistematicamente oposição a mim, faz uma calúnia e uma difamação do porte que ela fez hoje. E o senhor endossa. [...]

(09) Aécio Neves: Candidata, nem o fato de ter passado toda a sua vida longe de Minas Gerais justifica ofender tanto a realidade de Minas Gerais, candidata. $[. .$.

Para a situação própria do debate, a importância de explicitar a força ilocucionária (crítica, pergunta etc) ou o efeito perlocucionário (ofensa) da intervenção do outro está não apenas em revelar a interpretação do candidato responsável pelo comentário, mas em sinalizar como ele quer que o eleitor interprete o discurso do adversário ou de terceiros. Assim, ao acusar o adversário de criticar e ofender ou de endossar uma calúnia e uma difamação, o locutor tenta fazer crer que seu oponente não é um candidato idôneo e sério, não merecendo, portanto, a confiança do espectador/eleitor. 
EID\&A - Revista Eletrônica de Estudos Integrados em Discurso e Argumentação, Ilhéus, n. 12, jul/dez.2016.

Do ponto de vista da função que os $\mathrm{CM}$ exercem, todos os $\mathrm{CM}$ identificados no corpus até o momento desempenham papel importante no processo de negociação de faces (ou trabalho de face (GOFFMAN, 2011)). Em outros termos, no debate eleitoral a realização de um CM sempre tem reflexos na maneira como cada adversário busca construir sua imagem e atacar a imagem que o adversário tenta construir para si. Desse modo, o CM constitui sempre uma estratégia argumentativa importante com que cada candidato procura convencer o eleitor de que ele é a melhor alternativa para o cargo em disputa. Assim, a noção de estratégia argumentativa empregada neste trabalho para definir $\mathrm{O} C \mathrm{CM}$ se aproxima da noção de estratégia discursiva, tal como proposta por Roulet, Filliettaz \& Grobet (2001). Para os autores, é uma estratégia discursiva todo recurso textual e/ou linguístico que, numa dada interação, exerça papel no trabalho de face (ou processo de figuração (ROULET; FILLIETTAZ \& GROBET, 2001).

No processo de negociação de faces entre adversários políticos, os CM identificados no corpus recaem basicamente sobre três elementos da situação de comunicação própria do debate eleitoral. Por meio dos $\mathrm{CM}$, os candidatos: (i) avaliam negativa ou positivamente a maneira como o interlocutor (adversário ou integrante da plateia) escolheu construir sua intervenção, (ii) avaliam o comportamento (a linha de conduta) assumido pelos candidatos ao longo do debate ou mesmo ao longo da campanha eleitoral, (iii) evidenciam ter consciência de propriedades típicas (regularidades genéricas) da interação de que participam. Com base nos elementos avaliados, consideramos possível propor três subtipos de CM no debate eleitoral. Na sequência deste item, especificaremos cada um desses subtipos. Mas vale esclarecer que os subtipos são provisórios e não constituem classes estanques. Com a proposição dos subtipos, nosso objetivo é revelar semelhanças gerais identificadas no funcionamento de grupos dos $\mathrm{CM}$ encontrados no corpus até o presente momento da pesquisa.

\subsection{Subtipo 1}

No corpus, há um conjunto de CM por meio dos quais os candidatos avaliam negativa ou positivamente a maneira como o interlocutor (adversário ou integrante da plateia) escolheu construir sua intervenção. Quando a avaliação feita no $\mathrm{CM}$ recai sobre o adversário, o candidato busca evidenciar que seu oponente não deu uma resposta satisfatória, verdadeira e honesta ou 
EID\&A - Revista Eletrônica de Estudos Integrados em Discurso e Argumentação, Ilhéus, n. 12, jul/dez.2016.

tentou fugir da pergunta, adotando um comportamento "escorregadio". É o que mostra este trecho extraído do debate entre Haddad e Serra e formado por pergunta, resposta, réplica e tréplica. Os CM estão sublinhados.

(10) Fernando Haddad: [...] Eu queria saber se você como prefeito, governador, se sente responsável de alguma maneira por isso [aumento da criminalidade] ou se os seus sucessores têm alguma responsabilidade e o que pretende fazer pela segurança?

José Serra: $\mathrm{O}$ que eu devo dizer pela segurança é o seguinte, como prefeito eu vou da batalha, vou ser um prefeito ativista para ajudar o Governo do Estado na tarefa da segurança. [...]

Fernando Haddad: Bom, o candidato não respondeu a que atribui a escalada da violência no último ano. Dobrou o número de assassinatos na cidade de São Paulo.

José Serra: Como se vê a respeito de segurança é mais fácil criticar do que propor, porque efetivamente Fernando Haddad não propôs nada, mas nós propusemos e vamos levar à prática.

Após a resposta de Serra, Haddad a avalia, mostrando ao espectador que o adversário fugiu da pergunta (o candidato não respondeu a que atribui a escalada da violência no último ano). De modo semelhante, Serra inicia a tréplica, avaliando a réplica de Haddad como irrelevante ou como uma crítica vazia, porque não teria apresentado propostas (Como se vê a respeito de segurança é mais fácil criticar do que propor, porque efetivamente Fernando Haddad não propôs nada).

No debate entre Dilma Rousseff e Aécio Neves, ocorrem CM semelhantes a esses:

(11) Dilma Rousseff: Candidato, o senhor não respondeu. [...]

(12) Aécio Neves: Candidata, muito confusa essa sua explicação. [...]

Nos debates em que há plateia, como no debate entre Dilma e Aécio, espectadores costumam ser selecionados para fazer perguntas aos candidatos. Quando isso ocorre, essas perguntas também podem ser objeto de CM por parte dos candidatos. Nesses casos, a avaliação é sempre positiva e aponta para a pertinência da pergunta, como no exemplo (13).

(13) Dilma Rousseff: Luiz Alexandre, muito boa a pergunta. [...]

\subsection{Subtipo 2}

São comuns ainda os CM que avaliam o comportamento (a linha de conduta) assumido pelos candidatos ao longo do debate ou mesmo ao longo 
EID\&A - Revista Eletrônica de Estudos Integrados em Discurso e Argumentação, Ilhéus, n. 12, jul/dez.2016.

da campanha eleitoral. Exemplo bastante representativo desse tipo de $\mathrm{CM}$ é a troca de comentários apresentada no item anterior (exemplos (03) e (04)) em que Haddad e Serra avaliam o comportamento agressivo ou indignado do primeiro. Mas no debate entre Dilma Rousseff e Aécio Neves também ocorrem CM dessa natureza, como mostram estes exemplos (os CM estão sublinhados):

(14) Dilma Rousseff: [...] O senhor concorda com o que fala o seu candidato a Ministro da Fazenda, que diz que o salário mínimo está alto demais? Aécio Neves: Candidata, não é justo colocar palavras na boca de alguém que não está aqui para respondê-la. [...]

(15) Dilma Rousseff: Candidato, é fato que o senhor tem feito uma campanha extremamente agressiva a mim. Isso é reconhecido por todos os eleitores. [...]

(16) Aécio Neves: Candidata, a senhora traz agora, além da negação da resposta do que eu perguntei, acho o que Brasil merece saber o que a cidadã, o que a candidata Dilma acha em relação à condenação do mensalão, não sei por que tanto constrangimento. [...]

Com esse tipo de CM, o candidato, ao avaliar a linha de conduta assumida pelo adversário, busca atribuir a ele uma determinada imagem identitária (injusto ou leviano, agressivo, constrangido, inexperiente, grosseiro, ignorante etc). No exemplo (15), produzido por Dilma Rousseff, o segmento Isso é reconhecido por todos os eleitores indica que a finalidade desse tipo de CM é convencer o eleitor, conquistando sua concordância.

Outro exemplo representativo desse tipo de $\mathrm{CM}$, pelas implicações evidentes que tem para a negociação de imagens identitárias, é este trecho da fala de Haddad, que rebate propostas de Serra para a educação.

(17) Fernando Haddad: Serra, com o perdão da palavra, a educação não é propriamente a tua área. Professor não é reciclado nem treinado. Essas palavras não se adequam ao educador. O educador é formado, tem sua formação inicial, continuada. Reciclagem e treinamento você usa para outras coisas, você não pode usar para professor. Estou te orientando para você não cometer esse deslize novamente. [...]

Nesse trecho, Haddad avalia negativamente o uso que o adversário havia feito das palavras reciclagem e treinamento neste segmento: "nós vamos criar um centro de treinamento e reciclagem permanente dos professores do município. Para reforçar a qualidade das aulas, a qualidade da docência”. O trecho (17), produzido por Haddad, pode ser considerado um CM não porque faça uma avaliação do conteúdo semântico dessas palavras. Esse segmento é 
um CM porque, com ele, Haddad evidencia que o uso das palavras reciclagem e treinamento demonstra a ignorância do adversário sobre determinado aspecto da sociedade (educação) e de interesse para uma parcela da audiência do debate (os professores). 0 uso dessas palavras revelaria, assim, o despreparado de um candidato à prefeitura da cidade de São Paulo.

Como demonstra esse mesmo trecho da fala de Haddad, um CM pode avaliar o comportamento linguageiro do próprio locutor, ou seja, o locutor pode comentar sua própria linha de conduta, autoavaliando-se. Ao final do trecho, o segmento Estou te orientando para você não cometer esse deslize novamente constitui outro CM, por meio do qual Haddad revela que, com as ações linguageiras que realizou na porção textual que antecede esse segmento, ele estava dando orientações ao adversário. Em outros termos, esse CM recai não sobre o conjunto das informações expressas na porção textual anterior a ele, mas sobre o ato que o candidato realizou (dar orientação) com essa porção. Assim, como já apontado por Kotschi (1986), os CM podem ser auto-avaliativos, quando recaem sobre o próprio locutor, ou hetero-avalativos, quando recaem sobre outras instâncias enunciativas ou sobre elementos da situação de comunicação que não se confundem com o locutor.

No trecho em análise, tanto $\mathrm{O} C \mathrm{CM}$ hetero-avaliativo quanto o autoavaliativo constituem estratégias argumentativas importantes no ataque que Haddad promove à face de Serra. Isso porque, por meio desses CM, Haddad, primeiro, atribui ignorância ao adversário e, em seguida, o representa como um candidato que precisaria ser orientado pelo oponente em pleno debate eleitoral. Por isso, esse trecho tem fortes implicações para a negociação de imagens identitárias no debate ${ }^{5}$.

\subsection{Subtipo 3}

Em menor número, há CM que revelam a consciência dos candidatos quanto a propriedades típicas da interação de que participam. Nos comentários abaixo, o candidato Aécio Neves revela saber que fala para uma audiência bastante ampla (exemplo (18)) e que à prática social que é o debate subjaz um conjunto de expectativas ou normas relativas ao controle da distribuição dos turnos (intervenção sublinhada no exemplo (19)).

\footnotetext{
${ }^{5}$ Um estudo detalhado do papel desse trecho para a negociação de imagens identitárias entre Haddad e Serra encontra-se em Cunha (2014).
} 
EID\&A - Revista Eletrônica de Estudos Integrados em Discurso e Argumentação, Ilhéus, n. 12, jul/dez.2016.

(18) Aécio Neves: Mas nós estamos aqui falando para milhões e milhões de brasileiros. [...]

(19) Aécio Neves: [...] Quer dizer que a senhora é contra o financiamento privado.

Dilma Rousseff: Empresarial, candidato.

William Bonner: Candidata, a senhora precisa aguardar que ele responda.

Aécio Neves: Vamos manter as regras? [...]

O exemplo (19) é interessante, porque mostra como, no debate eleitoral, os candidatos se valem de toda e qualquer oportunidade para ganhar vantagens sobre o oponente. No exemplo, a candidata corrige o adversário no momento em que o direito de falar pertence a ele (Empresarial, candidato). Como represália por essa quebra das expectativas próprias do debate, o jornalista-moderador adverte a candidata (Candidata, a senhora precisa aguardar que ele responda). Ao retomar a fala, o candidato, para se beneficiar junto ao eleitor, inicia sua intervenção com o CM (Vamos manter as regras?), em que se refere às normas que subjazem ao debate. Com esse $C M$, que revela explicitamente a existência dessas normas, o candidato tenta mostrar ao eleitor que seu direito de falar foi violado por uma adversária que não saberia respeitar regras e que precisaria ser advertida pelos demais participantes da interação.

Esse CM tem grande impacto para a negociação de imagens identitárias. Afinal, um candidato que acusa o adversário de não saber ou querer seguir regras está aplicando um golpe contra a face de um pretendente a um cargo político, já que todo cargo dessa natureza envolve exatamente a obediência a uma série de deveres e regulamentos. Portanto, os CM com acusações de que o adversário estaria sendo impolido ou infringindo as normas do debate (o que não deixa de ser uma forma de impolidez) parecem ter um fim bem específico. Conforme Bourdieu (1982, 2014), o respeito a normas sociais, tais como fórmulas de polidez ou regras de boa educação, evidencia o respeito menos à pessoa que aparentemente se respeita e mais à ordem social mais ampla em que a interação ocorre. Nesse sentido, como atestam o exemplo anterior e outros CM encontrados em ambos os debates (cf. exemplos (03) e (15)), é esperado que aquele que supostamente infrinja normas sociais tácitas seja acusado pelo oponente, que tenta, com essa acusação, mostrar ao eleitor a incapacidade do adversário de representar a ordem social e zelar por ela. Isso explica porque no gênero debate eleitoral são frequentes não só as estratégias de polidez, mas também CM com acusações contra a suposta impolidez do adversário. 
EID\&A - Revista Eletrônica de Estudos Integrados em Discurso e Argumentação, Ilhéus, n. 12, jul/dez.2016.

\section{Considerações finais}

Neste trabalho, investigamos o papel que o comentário metadiscursivo, enquanto estratégia argumentativa, assume no debate eleitoral. Inicialmente, definimos o debate como uma prática social polêmica e o CM como uma relação de discurso em que o locutor liga a intervenção que produz a uma informação previamente estocada na memória discursiva, com o fim de avaliar positiva ou negativamente essa informação. Além disso, para poder ser caracterizado como metadiscursivo, o comentário precisa avaliar não a carga semântica de determinada porção textual, mas sim elementos relativos à situação de comunicação, tais como o desempenho dos candidatos na formulação de suas intervenções, as normas que subjazem ao debate ou mesmo à sociedade, as atitudes tomadas pelos interlocutores, a pertinência ou não da escolha de determinadas palavras etc.

Após a caracterização do $\mathrm{CM}$, procedemos ao estudo desse tipo de comentário em dois debates eleitorais. Promovidos pela mesma emissora de televisão, os debates foram protagonizados por Fernando Haddad (PT) e José Serra (PSDB), ao final da campanha para a prefeitura de São Paulo, em 2012, e Dilma Rousseff (PT) e Aécio Neves (PSDB), ao final da campanha para a Presidência da República, em 2014. As análises realizadas evidenciaram que o CM constitui uma estratégia argumentativa que possui uma função precisa, que é a de permitir a um candidato mostrar ao espectador que o adversário seria incapaz de seguir diferentes normas que estruturam nossa sociedade. Essas normas podem ser expectativas acerca do comportamento dos candidatos ao longo do próprio debate. Podem ser também normas ligadas a aspectos mais amplos do mundo social, como a maneira de se referir a determinada classe profissional.

Nessa perspectiva, o CM constitui um objeto de estudos relevante para os pesquisadores interessados em entender não só os mecanismos linguísticos característicos do gênero debate eleitoral, mas também a relação entre o uso desses mecanismos e a situação de comunicação em que são empregados. Afinal, o debate constitui uma cena criada pelos veículos de comunicação na qual o espectador é representado como uma instância poderosa, de cuja decisão dependeria a escolha do candidato que poderá ocupar e dirigir as administrações do Estado (CUNHA, 2016). Esse efeito é reforçado e ampliado pelo emprego das estratégias argumentativas de que os adversários políticos se valem para se golpearem, na medida em que todas 
EID\&A - Revista Eletrônica de Estudos Integrados em Discurso e Argumentação, Ilhéus, n. 12, jul/dez.2016.

têm como fim a conquista da confiança do eleitor. Constituindo uma dessas estratégias, o CM permite a cada um dos candidatos tentar, ao mesmo tempo, se apresentar ao eleitor como idôneo e confiável e apresentar o adversário como desonesto, "escorregadio" ou infrator de normas sociais.

\section{Referências}

AQUINO, Zilda G. O. Diálogos da mídia - o debate televisivo. In: PRETI, Dino (Org.). Diálogos na fala e na escrita. São Paulo: Humanitas, 2008. p. 171-194.

BERRENDONER, Alain. "Connecteurs pragmatiques" et anaphore. Cahiers de linguistique française, v. 5, p. 215-246, 1983.

BONU, Bruno. Les évaluations conversationnelles dans la narration. Revue québecoise de linguistique, v. 29, p. 51-69, 2001.

BOURDIEU, Pierre. Ce que parler veut dire. Paris: Fayard, 1982.

BOURDIEU, Pierre. Sobre o Estado. São Paulo: Companhia das Letras, 2014.

CHARAUDEAU, Patrick. Discurso político. São Paulo: Contexto, 2013.

CUNHA, Gustavo X. As relações retóricas e a negociação de faces em debate eleitoral. Confluência, n. 47, v. 2, p. 205-238, 2014.

CUNHA, Gustavo X. O papel das relações retóricas na negociação de faces em debate eleitoral. 2015. 17of. Relatório de pesquisa (Pós-Doutorado em Linguística) Faculdade de Letras, Universidade Federal de Minas Gerais, Belo Horizonte.

CUNHA, Gustavo X. O comentário metadiscursivo em debates eleitorais. Anais do IV Simpósio Internacional de Análise do Discurso. 2016, p. 01-16.

DUCROT, Oswald. 0 dizer e o dito. Campinas: Pontes, 1987.

FILLIETTAZ, Laurent. Actions, activités et discours. 2000. 403f. Tese (Doutorado em Linguística) - Faculdade de Letras, Universidade de Genebra, Genebra, 2000.

GOFFMAN, Erving. Ritual de interação: ensaios sobre o comportamento face a face. Petrópolis: Vozes, 2011.

JUBRAN, Clélia S. Especificidades da referenciação metadiscursiva. In: KOCH, Ingedore; MORATO, Edwiges M.; BENTES, Anna C. (Org.). Referenciação e discurso. São Paulo: Contexto, 2005. p. 219-242. 
EID\&A - Revista Eletrônica de Estudos Integrados em Discurso e Argumentação, Ilhéus, n. 12, jul/dez.2016.

KERBRAT-ORECCHIONI, Chaterine. Análise da conversação: princípios e métodos. São Paulo: Parábola Editorial, 2006.

KOTSCHI, Thomas. Procédés d'évaluation et de commentaire métadiscursifs comme stratégies interactives. Cahiers de Linguistique Française, n. 7, p. 207-230, 1986.

RISSO, Mercedes S.; JUBRAN, Clélia S. O discurso auto-reflexivo: processamento metadiscursivo do texto. DELTA, n. 14, p. 1-11, 1998.

ROULET, Eddy. Une approche modulaire de la problematique des relations de discours. In: MARI, Hugo et al. (Org.). Análise do discurso em perspectivas. Belo Horizonte: FALE/UFMG, 2003. p. 149-178.

ROULET, Eddy. The description of text relation markers in the Geneva model of discourse organization. In: FISCHER, Kerstin (Ed.). Approaches to Discourse Particles. Amsterdam: Elsevier, 2006. p. 115-131.

ROULET, Eddy; FILLIETTAZ, Laurent; GROBET, Anne. Un modèle et un instrument d'analyse de l'organisation du discours. Berne: Lang, 2001.

SILVA, Luiz Antonio. Descortesia e (des)construção da imagem pública. In: PRETI, Dino; LEITE, Marli Quadros (Org.). Comunicação na fala e na escrita. São Paulo: Humanitas, 2013. p. 93-120.

SOARES, Ivete B.; GOMES, Maria Carmem A. Efeito persuasivo da estrutura composicional no gênero debate eleitoral televisivo. Revista de Ciências Humanas, v. 7, n. 1, p. 69-83, 2008.

Forma de citação sugerida:

CUNHA, Gustavo Ximenes; BRAGA, Paloma Bernardino. O comentário metadiscursivo como estratégia argumentativa em debates eleitorais. EID\&A - Revista Eletrônica de Estudos Integrados em Discurso e Argumentação, Ilhéus, n. 12, p. 101-118, jul/dez.2016.

Recebido em: 24/10/2016

Aprovado em: 12/12/2016 